\title{
Automated Electron Tomography Using a Variety of Imaging Techniques and Detectors
}

\author{
S.T. Kim and W.J. de Ruijter \\ Emispec, 2050 S. Cottonwood Dr., Tempe, AZ 85282
}

The development of the first generation of automated electron tomography experiments has demonstrated vast improvements over manual approaches to acquiring tomographic single-axis tilt series $[1,2]$. However, the strategies employed in these solutions are aimed at improving acquisition efficiency, and neglect the onerous task of data analysis and visualization.

We have used Emispec's Cynapse platform [3] to develop a second generation of automated tomography experiments that integrate and streamline microscope setup, data acquisition and 3D reconstruction. By employing automation and integration strategies, we have realized benefits in speed, accuracy and ease of use. The evolution of automated electron tomography is highlighted in Table 1, which shows some of the strategies employed and their resulting efficiency gains.

Expanding upon our collaborative work in precalibrating TEM stages [4], the tomography component fully automates stage characterization and data collection. The concept of independently measuring the behavior of TEM stages is established as an alternative to performing in situ corrections for stage movements [5]. This precalibration has two major benefits. First, it dramatically reduces the amount of time required to collect a high-quality tilt series, outperforming previous automation strategies. Second, it allows automated electron tomography to be performed using a variety of imaging modes and detectors.

Manually operated HAADF STEM tomography has already been successfully demonstrated [6]. Using the approaches described above, we are now able to automate this experiment, with dramatic increases in speed and accuracy. The same strategies have also been applied to EFTEM tomography. Images from multiple energies can be acquired at every tilt angle, so employing a three-window background subtraction technique for multiple elements is possible.

We have integrated reconstruction with the component. Fine alignment of the tilt series is achieved by a fully automated procedure, increasing the overall efficiency compared to manual alignment routines. Reconstruction time can be reduced further through the use of parallel processing distributed over any number of networked Windows PC's. The reconstructed data can be exported directly into 3 rd party software dedicated to 3D visualization and rendering. An example is shown in Figure 1.

By integrating all the steps of a tomography experiment - setup, calibration, acquisition, reconstruction and visualization into a single tightly integrated environment, the entire experimental process is streamlined. Typical times for the entire process are approximately 30 minutes, improving the applicability and efficiency of tomography experiments. Bringing the experiments down to this time scale increases both the overall data throughput and the frequency of gathering exceptional data.

\section{References}

[1] A.J. Koster et al., Ultramicroscopy. 46 (1992) 207.

[2] K. Dierksen et al., Ultramicroscopy. 40 (1992) 71.

[3] J.K. Weiss and W.J. de Ruijter, Microscopy \& Microanalysis. (this issue) (2003).

[4] U. Ziese et al., Microscopy \& Microanalysis. 6 (2000) 1148.

[5] J. Pulokas et al., J. Struct. Biology. 128 (1999) 250.

[6] M. Weyland and P.A. Midgley, Microscopy \& Microanalysis. 7 (2001) 1162. 
TABLE 1. Comparison of representative times for various electron tomography experiment strategies.

\begin{tabular}{|c|c|c|c|}
\hline & MANUAL & $\begin{array}{l}\text { AUTOMATED } \\
\text { TOMOGRAPHY } \\
\text { GENERATION } 1\end{array}$ & $\begin{array}{l}\text { AUTOMATED } \\
\text { TOMOGRAPHY } \\
\text { GENERATION } 2\end{array}$ \\
\hline $\begin{array}{l}\text { Microscope setup } \\
\text { Eucentric height } \\
\text { Astigmatism } \\
\text { Beam center }\end{array}$ & $10-30$ minutes & $\begin{array}{l}\text { 10-30 minutes } \\
\text { (manual) }\end{array}$ & $\begin{array}{l}<5 \text { minutes } \\
\text { (automatic) }\end{array}$ \\
\hline \begin{tabular}{|l} 
Collection \\
Feature tracking \\
Focus tracking \\
Acquisition \\
\end{tabular} & many hours & $\begin{array}{c}\sim 1-2 \text { hours } \\
\text { (no precalibration) }\end{array}$ & $\begin{array}{c}10-20 \text { minutes } \\
\text { (precalibration) }\end{array}$ \\
\hline $\begin{array}{l}\text { Reconstruction } \\
\text { Copy/enter data } \\
\text { Series alignment } \\
\text { Calculate } 3-\mathrm{D} \text { volume }\end{array}$ & $\begin{array}{c}\sim 1-2 \text { hours } \\
\text { (one computer) }\end{array}$ & $\begin{array}{l}\sim 1-2 \text { hours } \\
\text { (manual entry, one } \\
\text { computer) }\end{array}$ & $\begin{array}{l}<5-10 \text { minutes } \\
\text { (automated, parallel } \\
\text { computing) }\end{array}$ \\
\hline
\end{tabular}
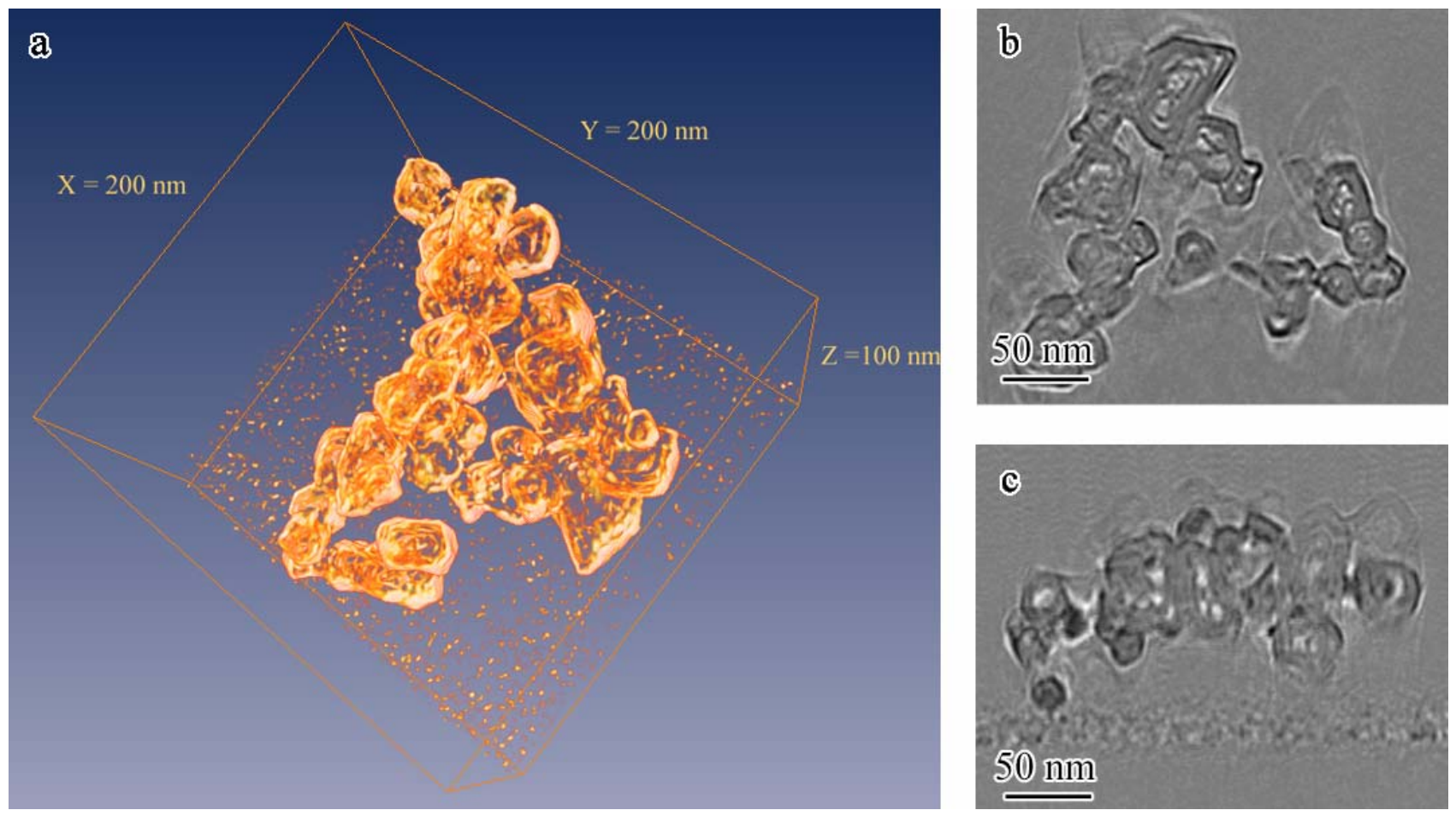

FIG. 1. Visualization of a reconstructed tomogram from a sample of graphite particles. The 3D rendering is shown in Fig. 1a. Slices taken along the XY- and XZ- planes are shown in Fig. 1b and $1 \mathrm{c}$, respectively. 